\title{
Entre a exposição e a descoberta: contribuições de Martha Dantas para o ensino de Matemática nas escolas
}

\author{
Between exposure and discovery: contributions \\ of Martha Dantas for the teaching of Mathematics in schools
}

Larissa Pinca Sarro Gomes ${ }^{1}$

\begin{abstract}
Resumo: Neste artigo apresenta-se uma reflexão a respeito do processo de escrita da coleção didática Matemática de autoria de Martha Dantas, Eliana Costa Nogueira, Neide Clotilde de Pinho e Souza, Eunice Guimarães e Omar Catunda. Os primeiros textos desta coleção começaram a ser escritos a partir de 1969 e se destinavam, a esta época, às quatro séries do ensino ginasial. Para conduzir esta investigação consideramos as formulações de Roger Chartier, Alain Choppin e Michel de Certeau. O estudo oportunizou compreender a estratégia dos autores, explicitada por Martha Dantas, para a escrita da coleção Matemática, na qual é realizada uma grande revisão de conteúdos, quando a comparamos com as coleções anteriores escritas por esses autores, e a proposta de uma metodologia que propõe romper com as aulas exclusivamente expositivas dos professores procurando incentivar a descoberta dos alunos.
\end{abstract}

Palavras-chave: Ensino de matemática. Livro didático. Martha Dantas. História da educação matemática.

\begin{abstract}
This paper presents a reflection on the process of writing the Mathematics didactic collection authored by Martha Dantas, Nogueira Eliana Costa, Neide Clotilde de Pinho and Souza, Eunice Guimarães and Omar Catunda. The first texts in this collection began to be written from 1969 and were designed, at this time, for the four years of fundamental school. To conduct this research we consider the backgrounds of authors of Cultural History as Roger Chartier, Alain Choppin and Michel de Certeau. The study allowed understanding the strategies of the authors, explained by Martha Dantas, for writing the Mathematics collection, which covers a large revision of contents, when compared with the previous collections written by these authors. In addition, to understand a methodology that proposes to break the lecture-only style of teachers and seeks to encourage discovery by the students.
\end{abstract}

Keywords: Mathematics teaching. Textbook. Martha Dantas. History of Mathematics education.

\footnotetext{
${ }^{1}$ Universidade Estadual de Santa Cruz (UESC), Departamento de Ciências Exatas e Tecnológicas, Programa de Pós-graduação em Educação Matemática, Ilhéus, BA, Brasil. E-mail: <lpsgomes@uesc.br>.
} 


\section{Introdução}

A coleção didática intitulada Matemática foi escrita por um grupo de professores da Universidade Federal da Bahia, que começou a produzir textos didáticos destinados à matemática escolar, em 1964. Essa coleção, de autoria de Omar Catunda, Martha Maria de Souza Dantas, Eliana Costa Nogueira, Neide Clotilde de Pinho e Souza e Eunice da Conceição Guimarães começou a ser utilizada nas escolas na segunda metade da década de 1970 e se destinava a alunos que estivessem cursando as quatro últimas séries do que atualmente conhecemos como Ensino Fundamental.

Serão apresentados os estudos realizados com a base documental constituída com o propósito de compreender como se deu o processo de escrita da coleção Matemática e, em particular, a maneira como Martha Dantas defende suas intenções para a escrita da coleção frente às diferentes propostas de mudanças destinadas à matemática escolar.

Para conduzir este estudo, foram consideradas as orientações de Choppin (2004, p. 554), que ressalta, aos pesquisadores que se propõem investigar os livros didáticos, a importância de recolocá-los “[...] no ambiente em que foram concebidos, produzidos, distribuídos, utilizados e recebidos". Segundo o autor, a investigação que se propõe segue a perspectiva que passou a ser considerada a partir dos anos 1970, quando Choppin (2004, p. 558) identificou uma mudança progressiva de perspectiva na análise dos conteúdos dos livros didáticos, com os pesquisadores se interrogando a respeito das “[...] finalidades do ensino, sobre seus conteúdos e métodos e, entre outras coisas, a colocarem aos antigos manuais escolares questões de natureza epistemológica e didática".

Também foram consideradas as formulações de Chartier (1990, p. 26), que apontam para a relevância de se colocar a noção de apropriação no "[...] centro de uma abordagem de história cultural que se prende com práticas diferenciadas”, permitindo interpretar como se deu o processo de produção da coleção didática Matemática buscando compreender as apropriações dos autores relacionadas às propostas de mudanças da Matemática escolar. De acordo com esse autor, a apropriação tem por objetivo "[...] uma história social dos usos e das interpretações, referida às suas determinações fundamentais e inscrita nas práticas específicas que as produzem" (CHARTIER, 1990, p. 26).

Dessa forma, Chartier (1990) considera relevante compreender as diversas formas pelas quais um mesmo texto pode ser interpretado por seus leitores, em particular, neste artigo, há o interesse em compreender a maneira como os autores se apropriam dos debates para as mudanças relacionadas aos conteúdos matemáticos e aos métodos de ensino da Matemática escolar, ressignificando-os a partir de suas vivências e experiências inscritas em situações históricas e sociais diferenciadas.

No contexto deste trabalho, foi possível interpretar que os autores da coleção Matemática estão na posição estratégica, ao produzirem um novo material para ser utilizado nas escolas. Conforme sugere Certeau (2008, p. 92), as operações estratégicas estão sempre relacionadas a um lugar de poder e são "capazes de produzir, mapear e impor". Com esse autor, também se compreende a diversidade dos usos feitos dos materiais didáticos em tempos e espaços escolares distintos, o que Certeau chama de táticas de apropriação. No entanto, a investigação das táticas de apropriação, ou da maneira como são utilizados e recebidos os livros didáticos, conforme ressalta Choppin, requer uma investigação prévia das estratégias às quais as práticas cotidianas estão submetidas. Por esse motivo, neste artigo, limitou-se a investigar as estratégias 
defendidas, em particular, por Martha Dantas, para a escrita de uma nova proposta de ensino de Matemática. As táticas de apropriação dos professores ao utilizarem a coleção didática em suas aulas são discutidas em Gomes e Miorim (2015).

\section{A constituição da base documental}

Com as buscas iniciais por documentos que ajudassem a conduzir essa investigação, foram localizados os quatro volumes da coleção Matemática em um sebo da cidade de Ilhéus, local onde a coleção foi utilizada por uma instituição escolar. Os autores da coleção didática Matemática são mencionados na capa de cada um dos seus quatro volumes. Martha Maria de Souza Dantas é a primeira autora que aparece, seguida por Eliana Costa Nogueira, Neide Clotilde de Pinho e Souza, Eunice da Conceição Guimarães e Omar Catunda. Logo abaixo dos nomes dos autores já aparecem algumas intenções dos autores que são apresentadas em uma imagem com três retas que se intersectam formando um triângulo. No interior desse triângulo aparece a frase "Os porquês são enfatizados" e, nos demais espaços determinados pela intersecção das retas, aparecem as frases: "Harmoniza a exposição com a descoberta", "Leva o aluno a estudar sozinho" e "Desenvolve o pensamento crítico e criativo".

Após esse momento inicial, buscou-se por textos que ajudassem a compreender a proposta de ensino de Matemática defendida por esse grupo que já trabalhava junto desde a segunda metade da década de 1960. Considerando os apontamentos de Chartier e Choppin, avaliou-se ser relevante compreender como o ensino de Matemática estava sendo por eles pensado e re(elaborado). Para isso, foram localizadas as outras coleções publicadas por esse grupo de autores. Trata-se das coleções Matemática moderna (1968-1969), Ensino atualizado da matemática: curso ginasial (1970-1971) e Ensino atualizado da matemática, destinado à 5. ${ }^{\mathrm{a}}, 6 .^{\mathrm{a}}$, 7. $^{\mathrm{a}} \mathrm{e}$ 8. ${ }^{\mathrm{a}}$ séries do primeiro grau (1975).

A busca por esses documentos iniciou-se na Biblioteca Central da Universidade Federal da Bahia (UFBA) e em sebos da capital baiana, onde se procurou localizar as coleções publicadas pelo grupo de autores de interesse nesta pesquisa. Foi também na Biblioteca Central da UFBA que foi encontrada a tese de Martha Dantas (1971) Sobre a metodologia da matemática, e vários depoimentos e artigos importantes para a investigação, que foram publicados a partir da segunda metade da década de 1980, no periódico intitulado Cadernos do Instituto de Física da Universidade Federal da Babia. Dentre esses depoimentos, ressaltam-se os de Martha Dantas e Omar Catunda, os dois autores que coordenaram a escrita dos livros didáticos. Também foi considerado o periódico Cadernos do Instituto de Estudos e Pesquisas em Educação Anísio Teixeira, que apresenta artigos de Martha Dantas nos quais a professora de Matemática baiana avalia, na década de 1980, a introdução de conteúdos da Matemática Moderna na escola secundária.

Com a seleção e a leitura desses documentos e com o objetivo de investigação definido, este estudo se movimentou no sentido de compreender como os autores chegaram a um consenso a respeito da apresentação dos conteúdos e do método de ensino a serem apresentados na coleção Matemática, que foram por eles considerados “indispensáveis para dar cumprimento às programações oficiais"2.

\footnotetext{
${ }^{2}$ Texto apresentado antes do Sumário nos quatro livros da coleção Matemática publicada pela Editora Contraste.
} 
Para a escrita da história que se propõe, foram considerados os caminhos sugeridos por Certeau (2010, p. 81):

Em história, tudo começa com o gesto de separar, de reunir, de transformar em documentos certos objetos distribuídos de outra maneira. Esta nova distribuição cultural é o primeiro trabalho. Na realidade, ela consiste em produzir tais documentos, pelo simples fato de recopiar, transcrever ou fotografar estes objetos mudando ao mesmo tempo o seu lugar e o seu estatuto.

\section{As primeiras publicações: maneiras de escrever}

O primeiro material didático produzido pelos autores da coleção Matemática intitulava-se Projeto para o ensino atualizado da matemática em nivel secundário e começou a ser elaborado em 1964 (DANTAS, 1996, p. 64). Martha Dantas relembrou que as primeiras pesquisas ${ }^{3}$ foram realizadas por Eliana Costa Nogueira, Neide Clotilde de Pinho e Souza, Eunice da Conceição Guimarães e Norma Coelho de Araújo, graduadas em Matemática pela então Faculdade de Filosofia da Universidade da Bahia, sendo que as três primeiras tinham sido alunas da professora Martha Dantas na disciplina Didática Especial da Matemática (FREIRE, 2009, p. 63). Nos primeiros textos escritos também foi encontrada a participação de Maria Augusta de Araújo Moreno como autora.

A motivação para a elaboração desses textos didáticos surgira em decorrência dos debates que se intensificaram a partir da década de 1950 e que, conforme relembrou Dantas (1993, p. 23), buscavam apresentar “[...] uma nova Matemática, que é mais simples, porque mais sintética, mais geral e, consequentemente, mais abstrata”. Além da elaboração de novos textos, a professora baiana apontou para a necessidade de treinamento dos professores aos novos programas porque a própria Matemática havia mudado. "A sua linguagem era a linguagem dos conjuntos, o seu objeto era o estudo da estrutura, o seu método era o método axiomático" (DANTAS, 1993, p. 23).

Desde os primeiros trabalhos, essa equipe contou com as orientações de Martha Dantas e Omar Catunda. Esse último já era um matemático experiente e engajado nos debates para a condução de mudanças na Matemática escolar. Entre 1934 e 1962, Catunda atuou como professor da Universidade de São Paulo (USP), fazendo parte do corpo docente do Departamento de Matemática da Faculdade de Filosofia, Ciências e Letras (FFCL). Sua mudança para Salvador foi possível porque ele já havia cumprido mais de trinta anos no serviço público, tempo suficiente para solicitar a aposentadoria, finalizando suas atividades na USP.

\footnotetext{
${ }^{3}$ A autora deste artigo interpreta que a referência às "pesquisas" voltadas para o ensino de Matemática está relacionada às atividades do grupo, que se encontravam na posição estratégica de elaborar uma proposta de ensino, considerando os novos conteúdos matemáticos e a maneira como esses conteúdos deveriam ser apresentados nas escolas. Além disso, os professores do Centro de Ensino de Ciências da Bahia (CECIBA) realizavam experimentações dos textos por eles produzidos com os alunos do Colégio de Aplicação da UFBa.
} 
Ao desembarcar em Salvador, no dia 13 de janeiro de 1963, Catunda estava disponível para assumir as atividades de ensino e pesquisa no Instituto de Matemática e Física (IMF) da UFBa, exercendo suas funções como Professor Titular até sua aposentadoria compulsória, em setembro de 1976. Dentre as atividades no IMF, Catunda discutia questões relacionadas ao ensino secundário com Martha Dantas (CATUNDA, 1985, p. 92-94).

A essa época, Martha já havia conhecido os métodos de ensino e conteúdos matemáticos utilizados por professores de Matemática da Bélgica, França, Inglaterra e Portugal. Além disso, ela e Catunda participavam de fóruns científicos nacionais e internacionais voltados ao debate da Matemática escolar, inclusive como oradores.

No entanto, pôde-se apreender nos depoimentos de Martha Dantas que, apesar de já terem tido essas experiências, as estratégias dos autores para a produção das primeiras coleções estão muito centradas nas concepções de ensino de Matemática de Catunda. Em diversas ocasiões, a professora de Matemática baiana mencionou ser de Catunda “[...] as demonstrações originais do trabalho de Geometria" (DANTAS, 1971, p. 28).

De acordo com Freire (2009, p. 72-73), a partir das avaliações realizadas com as experimentações dessas primeiras apostilas, cujo processo foi iniciado em 1966, o material passou por modificações que resultou na edição da primeira coleção didática desse grupo de professores, para as quatro séries do curso ginasial, contemplando o mesmo título dos textos apostilados: Matemática moderna. A coleção tinha, entre seus autores, Omar Catunda, Martha Dantas, Eliana Nogueira, Neide Clotilde Souza e Eunice Guimarães.

Além da coleção Matemática moderna, a equipe de professoras e Catunda publicaram, ainda em 1970, os quatro volumes da coleção Ensino atualizado da matemática: curso ginasial, pela EDART de São Paulo, conforme cita Martha Dantas nas referências de sua tese. No entanto, apenas o primeiro volume da coleção, com essa data de publicação, foi localizado na biblioteca central da UFBa. Os outros volumes foram localizados, mas o ano de publicação é 1971 e não há qualquer referência de que seja a segunda edição da obra.

$\mathrm{Na}$ contracapa do primeiro volume aparece o nome de Omar Catunda e, logo abaixo, o cargo que ocupava na Universidade Federal da Bahia - Diretor do Instituto de Matemática e Física da UFBa -, seguido dos nomes das autoras - Martha Maria de Souza Dantas, Eliana Costa Nogueira, Norma Coelho de Araújo, Eunice da Conceição Guimarães e Neide Clotilde de Pinho e Souza - e da descrição "Professores do Centro de Ensino de Ciências da Bahia - CECIBA". A última autora que aparece - Maria Augusta de Araújo Moreno - é seguida da descrição "Professora de Matemática do Colégio de Aplicação da UFBa". O segundo, terceiro e quarto volumes dessa coleção também foram publicados pela EDART de São Paulo, em 1971. O quarto volume apresenta os mesmos autores e apresentação do primeiro volume. No segundo e terceiro volumes, a autora Maria Augusta de Araújo Moreno não é mencionada. Ao comparar os sumários dos quatro volumes dessa coleção com os da coleção Matemática moderna, Freire (2009, p. 73) constatou "quase total similaridade dos conteúdos propostos".

Os conteúdos considerados fundamentais nesses primeiros textos didáticos consistiam no domínio da linguagem dos conjuntos, nas estruturas algébricas e nas transformações geométricas, essas últimas apontadas como uma importante ferramenta para o ensino da geometria.

Em particular, o estudo das transformações geométricas foi privilegiado desde os primeiros textos didáticos produzidos pelo grupo e se manteve como um conteúdo importante até as últimas obras desse grupo, publicadas na década de 1990. Dantas (1996, p. 125) relembrou 
por diversas vezes ter sido essa uma recomendação feita no final do século 19, por Felix Klein, e que esse matemático "[...] afirmava que o conceito de transformação desempenhava um amplo papel simplificador e coordenador no estudo da Geometria”.

Outros matemáticos e educadores contemporâneos de Martha Dantas, e com quem ela manteve contato, também defendiam o ensino da geometria pelas transformações geométricas, como Silva (1950), em seu livro Transformacõos geométricas, e Félix (1960, 1966) em seus livros Exposé moderne des mathématiques élémentaires e Mathématiques modernes: enseignement élémentaire.

Para o estudo dos conjuntos numéricos, os autores explicam que suas intenções com a escrita da coleção, destinada ao ensino ginasial, era o de ampliar o campo dos números, partindo dos números naturais, apresentados no primeiro volume da coleção, até chegar ao conjunto dos números reais no terceiro volume. Com o estudo das operações definidas nos diferentes conjuntos numéricos, Martha defende que é possível a introdução das estruturas algébricas desde a primeira série ginasial e essas estruturas poderiam ser enunciadas e ampliadas nos anos seguintes, após o estudo das propriedades das operações definidas em conjuntos numéricos - naturais, inteiros, racionais, reais e complexos -, e em transformações geométricas na reta e no plano. A justificativa para o estudo de estruturas no ensino secundário é apresentada por Dantas (1971, p. 25), da seguinte forma:

[...] os alunos se habituam a procurar nos conjuntos estudados, para as operações definidas, as estruturas existentes e o ensino da Matemática alcança mais um dos seus objetivos - ressaltar o papel unificador das estruturas - e a conseqüente economia que resulta da não duplicação de demonstrações ou verificações concernentes aos mais diversos conjuntos de pontos, números, transformações, polinômios, etc. - que possuem a mesma estrutura.

Em meio às manifestações contrárias ao movimento de modernização da Matemática, uma nova edição atualizada da coleção é publicada pela equipe liderada por Martha Dantas e Catunda, agora com o título Ensino atualizado da matemática, destinada à 5. ${ }^{a}, 6 .^{a}, 7 .^{a}$ e 8..$^{a}$ séries do primeiro grau. Acompanhando as novas orientações de nomenclatura nacionais divulgadas na Lei no 5692, de 11 de agosto 1971 (BRASIL, 1971), a coleção foi lançada pela EDART, em 1975. Os autores que aparecem na capa são: Omar Catunda, Martha Maria de Souza Dantas, Eliana Costa Nogueira, Norma Coelho de Araújo, Eunice da Conceição Guimarães e Neide Clotilde de Pinho e Souza.

$\mathrm{Na}$ avaliação de Camargo (2009, p. 110), ao analisar o terceiro e quarto volumes dessa coleção, é possível identificar "algumas alterações na organização dos conteúdos". A autora aponta a retirada de conteúdos como o estudo das transformações na reta real, os estudos do espaço afim, vetores dependentes, independentes e equação da reta. E ressalta a manutenção de outros como as noções de lógica, o tratamento via estruturas algébricas, o uso das propriedades da teoria de conjuntos, os conteúdos, o tratamento e a metodologia da geometria euclidiana, e as transformações geométricas associadas ao conceito de vetores, sendo que não é mais explorado o tratamento algébrico. O uso do papel quadriculado é introduzido como recurso metodológico auxiliando no ensino da geometria (CAMARGO, 2009, p. 112-116).

Ainda na década de 1970, para a continuidade das "pesquisas", Dantas (1996, p. 66) apontou, em suas rememorações da década de 1990, que o grupo considerou "[...] as críticas 
que, internacionalmente, se faziam ao ensino da Matemática Moderna” e recomendavam “[...] um retrocesso do caráter abstrato, formal e dedutivo, com que se tratavam as estruturas matemáticas e uma maior concentração sobre sua compreensão e sua aplicação".

Alguns excessos foram reconhecidos pelos autores a partir da experimentação das primeiras coleções didáticas em outras escolas públicas da capital baiana, além do Colégio de Aplicação da Universidade da Bahia, onde a experimentação havia iniciado, em 1966. Na avaliação de Dantas (1993, p. 24), a experimentação no Colégio de Aplicação havia tido sucesso, pois "os professores que a realizaram estavam preparados para tal e os alunos tinham condições para utilizar os novos textos”. Dantas (1993, p. 27) também declarou:

[...] muito aprendi com Catunda da Matemática que a Faculdade de Filosofia não me ensinou. Aprendi, também, de filosofia de vida e responsabilidade profissional. Acho que só não aprendi didática mas creio que o fiz sentir um pouco que muitas das abstrações que lhe eram familiares não me eram familiares.

Essas declarações de Martha talvez permitam compreender o excesso de formalismo e a tendência para a abstração que marcaram as primeiras produções do grupo, que foram produzidas no Centro de Ensino de Ciências da Bahia (CECIBA) durante o período de seu funcionamento, entre 1965 e 1969.

\section{Um novo projeto para o ensino de matemática}

Em decorrência da implantação da Reforma Universitária na universidade da capital baiana, em 1968, muitas mudanças aconteceram e "todos os professores de Matemática da UFBA, que atuavam nos departamentos de Matemática espalhados por todas as suas escolas e faculdades, foram realocados no novo Instituto de Matemática” (DIAS, 2002, p. 225). Essas mudanças também afetaram as atividades coordenadas por Martha Dantas, que já havia trabalhado na Faculdade de Filosofia, no IMF, e, em 1969, estava fazendo parte do corpo docente da Faculdade de Educação (FACED), da Universidade Federal da Bahia, onde permaneceu até sua aposentadoria em 1977 (DANTAS, 1996, p. 68-69).

Também trabalhavam na FACED as professoras Eliana Costa Nogueira e Neide Clotilde de Pinho e, juntamente com Martha, eram as professoras responsáveis pela disciplina Metodologia do ensino da Matemática oferecida pela FACED, e integravam um programa de extensão intitulado Programa de Treinamento e Aperfeiçoamento de Professores de Ciências Experimentais e Matemática (PROTAP). Essas professoras, juntamente com Eunice da Conceição Guimarães, que pertencia ao Instituto de Matemática da UFBa, iniciaram o trabalho com um processo de ensino denominado Processo entre a Exposição e a Descoberta (PROED). (DANTAS, 1996, p. 68-69).

O projeto PROED surgiu em um período marcado por intensas críticas ao Movimento da Matemática Moderna e pela publicação do livro escrito por Morris Kline, com o título Why Johnny can't add: the failure of the new math. O livro foi publicado no Brasil, em 1976, com o título O fracasso da matemática moderna (KLINE, 1976). Nele, o autor enfatiza que a Matemática Moderna agravara um dos problemas do currículo tradicional - a falta de motivação para o estudo 
da Matemática. E avaliou que a proposta da moderna Matemática era "[...] motivar o jovem a aprender Matemática com mais Matemática” (KLINE, 1976, p. 126-127). O autor também ressalta que "[...] a mente humana não opera na Matemática diferentemente do pensamento político ou social" (KLINE, 1976, p. 126-127) e exemplifica dizendo que, ao "pregar a fraternidade entre os homens", não se tem garantias de que as pessoas a tenham compreendido e a pratiquem se não a vivenciaram. De maneira análoga, aos estudantes para os quais se "[...] ensinam abstrações antes de eles terem adquirido a rica experiência que, de fato, conduzem a essas abstrações, poderão obter um conhecimento superficial” (KLINE, 1976, p. 126-127).

As ponderações de Kline nos remetem a duas grandes questões que oscilam entre os conteúdos que devem constar nos currículos escolares, em decorrência do conhecimento matemático produzido nos séculos 19 e 20, e os ajustes necessários para sua apresentação nas escolas. Os fóruns científicos internacionais e nacionais apontavam para algumas diretrizes de conteúdos a serem introduzidos, fornecidas por matemáticos que tinham suas pesquisas reconhecidas no meio acadêmico e buscavam apoio nos estudos psicológicos e pedagógicos da época. No entanto, não havia entre os matemáticos uma única orientação para a apresentação dos novos conteúdos. Muitos excessos foram cometidos, tanto na universidade como nas escolas.

Ainda na década de 1970, para a continuidade das "pesquisas", Dantas (1996, p. 66) apontou em suas rememorações da década de 1990 que o grupo considerou "as críticas que, internacionalmente, se faziam ao ensino da Matemática Moderna” e recomendavam "[...] um retrocesso do caráter abstrato, formal e dedutivo, com que se tratavam as estruturas matemáticas e uma maior concentração sobre sua compreensão e sua aplicação" (DANTAS, 1996, p. 66).

Para Martha Dantas, que acompanhava ativamente o processo de mudanças da Matemática escolar desde a década de 1950, era preciso colocar "[...] um ponto final em mudanças radicais” (DANTAS, 1966, p. 66). Citando matemáticos como René Thom, Peter Hilton e Douglas Quadling, ressaltou que todos eles reconheceram a importância de apresentar os novos conceitos matemáticos aos alunos nas escolas no entanto, ressaltou que era preciso se preocupar com o modus faciendi.

Uma nova revisão dos conteúdos e uma grande mudança metodológica foram feitos pela equipe de professoras baianas e Catunda. As novas propostas de conteúdo e método de ensino foram apresentadas com a publicação da coleção Matemática.

\section{A coleção Matemática}

Martha Dantas defendeu a nova metodologia proposta na coleção Matemática em seu livro destinado aos professores, publicado em 1987, sob o título Ensino da matemática: um processo entre a exposição e a descoberta (DANTAS, 1987). A descoberta, e também o método heurístico, já tinham sido apresentados como elementos importantes no processo de ensino da Matemática por essa autora. No discurso proferido por Dantas durante a abertura do primeiro encontro nacional destinado ao ensino de Matemática, em 1955, ela defendeu o "método heurístico" em oposição ao "método dogmático". Segundo Martha, no primeiro, “[...] tudo toma caráter de descoberta" enquanto no segundo "tudo toma aspecto de verdade revelada, em que é preciso acreditar, obedecer às regras, saber os teoremas de cor, agir depressa e não errar" (DANTAS, 1967, p. 248). 
Em outra oportunidade, em sua tese publicada em 1971, Martha defendeu que o projeto por ela orientado nessa época permitiria "[...] levar o aluno, desde a primeira série ginasial, a descobrir, utilizando sempre um processo heurístico, as estruturas existentes em $\mathrm{N}, \mathrm{Q}^{+}, \mathrm{Z}, \mathrm{Q}$, R, C, conjuntos estudados no curso secundário” (DANTAS, 1971, p. 20).

$\mathrm{Na}$ coleção Matemática, os autores apresentaram como proposta um processo de ensino de Matemática que foi por eles explicitado em um texto intitulado Alguns dados sobre o livro, localizado antes do sumário. Nesse texto, os autores explicaram que "[...] a atividade do aluno é provocada ao máximo através de perguntas que devem ser respondidas por ele e de tarefas que ele deve cumprir, trabalhando sozinho" (DANTAS, 19--, p. 3). Para viabilizar essa proposta, os autores elaboraram os novos textos dessa coleção, organizados em fichas, que orientavam os alunos no processo da descoberta, e ressaltaram a importância do professor na avaliação das fichas e na "análise de diferentes processos de resolução de problemas e exercícios, encontrados pelos alunos" (DANTAS, 19--, p. 3). Nas palavras dos autores, no texto de apresentação dos quatro volumes publicados pela Editora Contraste, “[...] espera-se que o processo metodológico utilizado em cada ficha, processo que harmoniza a 'exposição' com a 'descoberta', leve o aluno a estudar sozinho" (DANTAS, 19--, p. 3).

Essa apresentação do conteúdo por meio de fichas de estudo proporcionava uma nova abordagem para os conteúdos matemáticos, possibilitando uma ruptura com as aulas exclusivamente expositivas, substituindo-as pelo estudo individual ou em grupo, e também fazendo uso, quando necessário, da exposição. A proposta dos autores estava bem definida desde o título do projeto que culminou com a escrita da coleção Matemática: processo entre a exposição e a descoberta.

$\mathrm{Na}$ apresentação dos livros, os autores também destacam que "[...] cada Ficha constitui uma unidade de trabalho na qual, em geral, se pretende que um conceito seja definido, uma regra seja estabelecida ou uma propriedade seja induzida" (DANTAS, 19--, p. 3).

Uma análise da capa dos quatro volumes da coleção Matemática já acenou para algumas decisões de seus autores, conforme já mencionado. Em cada volume, logo abaixo do nome dos autores, aparecem as frases: "os porquês são enfatizados"; "harmoniza a exposição com a descoberta"; "leva o aluno a estudar sozinho"; e "desenvolve o pensamento crítico e criativo".

Com esse propósito, em cada ficha de estudo o aluno é solicitado a ler, interpretar, elaborar e redigir suas respostas em espaços reservados no próprio livro. Aos professores, caberia o papel de orientadores analisando as diferentes resoluções das atividades elaboradas pelos alunos e, nesse processo, o uso do quadro negro "[...] passa a ser utilizado como uma peça auxiliar" (DANTAS, 19--, p. 3). Essa era a proposta dos autores para harmonizar a exposição com a descoberta, conduzindo o aluno a estudar sozinho.

Para Dantas (1996, p. 76), com o uso da "coletânea de fichas", o "caderno de notas" poderia ser eliminado e o aluno ficaria de "posse de um documento" que poderia ser por ele consultado nas séries seguintes para buscar respostas para "seus porquês". A autora também ressaltou que "a atividade pessoal do aluno" deveria ser "provocada ao máximo, respeitando o seu ritmo".

Os recursos gráficos dos quatro volumes da coleção Matemática são bastante simples e, apesar das figuras e dos textos não serem coloridos, o destaque para definições e propriedades importantes são realizados com uma moldura retangular envolvendo o texto que se pretende destacar. O diálogo dos autores com os alunos é uma característica identificada em todos os livros dessa coleção, no qual os alunos são interrogados a respeito das leituras que fazem do texto. 
A primeira experimentação da coleção Matemática, relembrada por Dantas (1996, p. 78), foi realizada em 1975, no Colégio Estadual Duque de Caxias, em Salvador. Outras experiências também foram apontadas pela principal articuladora do grupo, que estava atenta aos colégios que ainda utilizavam as edições atualizadas dessa coleção nas décadas de 1980 e 1990.

Martha Dantas também participava de diversos fóruns científicos nacionais e internacionais e, em seus depoimentos, relembrou o contato frequente que teve durante sua trajetória profissional com os professores de Matemática dos diversos níveis de ensino. Isso fica claro nas referências que traz no livro de sua autoria, nas quais cita os últimos Congressos Internacionais de Educação Matemática dos quais participara, que aconteceram em Lyon (França), 1969, Exeter (Reino Unido), 1972 e Karlsruhe (Alemanha), 1976. Do encontro em Lyon, Martha apontou a exposição do professor Gauthier, que propôs a utilização de uma técnica de aprendizagem pessoal na qual eram utilizadas fichas de trabalho. Dessa exposição, Martha Dantas afirmou ter se inspirado para a elaboração dos novos textos da coleção Matemática. Da proposta das fichas, apresentadas por Gauthier, a autora de didáticos relembrou que "[...] não eram apropriadas para os nossos alunos por não darem informações suficientes para a redescoberta dos conceitos abordados" (DANTAS, 1996, p. 69). Destacou a importância de o aluno descobrir por esforço próprio a solução de um problema enfatizando que, "Se o aluno é colocado na situação de descobrir, por ele mesmo, o conceito, a regra, o princípio, etc., a partir de uma apresentação apropriada de exemplos, de contra-exemplos e de material didático, ele será capaz de utilizá-los, independentemente, em novas situações” (DANTAS, 1987, p. 14).

Com sua vasta experiência com as coleções anteriores e do contato com a sala de aula, Martha Dantas advertiu que esse processo exigiria mais tempo e nem sempre o aluno poderia descobrir tudo sem o auxílio do professor e de uma orientação para uma "descoberta dirigida" que demandaria "textos devidamente elaborados para essa finalidade" (DANTAS, 1987, p. 15).

É interessante observar que os autores não faziam referência ao estudo dirigido, mas a uma "descoberta dirigida". Essa distinção, que foi ressaltada, em particular por Martha Dantas, começou a fazer sentido ao se compreender como os autores de livros didáticos expressavam essa tendência pedagógica em suas coleções nas décadas de 1970 e 1980, dando ênfase à tendência tecnicista.

Essa tendência era conhecida pela professora de Didática da Matemática, Martha Dantas, e não fazia parte das concepções de ensino e aprendizagem que defendia, desde a década de 1950, nos fóruns científicos nacionais e internacionais dos quais participava, e também em suas publicações. Por esses motivos, avalia-se que a referência de Martha Dantas a uma "descoberta dirigida" seria o resultado das apropriações e ressignificações por ela elaboradas, e também pelos outros autores, a partir de suas experiências como professores e autores de livros didáticos.

A coleção Matemática não foi a única publicação da equipe liderada por Martha e Catunda a apresentar fichas de estudo. Foi localizado um guia destinado ao professor intitulado Matemática 2. ciclo: ensino atualizado, publicado em 1975, de autoria de Omar Catunda, Martha Maria de Souza Dantas, Eliana Costa Nogueira, Norma Coelho de Araújo, Eunice da Conceição Guimarães e Neide Clotilde de Pinho e Souza, no qual os autores apresentam algumas fichas como sugestão para o trabalho do professor com os alunos. $\mathrm{Na}$ introdução, os autores explicaram que o guia se destinava a apoiar os professores que utilizavam em suas aulas os três volumes da coleção que tinham o mesmo título do guia e eram desginados ao segundo ciclo 
do secundário ${ }^{4}$. As fichas sugeridas pelos autores poderiam ser utilizadas na abordagem dos seguintes conceitos: translações no espaço, espaço afim, sistema de referência no espaço e transformações no espaço afim. Apesar da sugestão dos autores apresentada no guia, a coleção Matemática 2. ${ }^{\circ}$ ciclo: ensino atualizado não estava organizada em fichas de estudo. Essa nos pareceu ser a primeira experiência do grupo no trabalho com fichas de estudo.

Para tornar viável a abordagem sugerida pelos autores, Dantas (1987, p. 15) havia reconhecido que era "necessário elaborar programas com conteúdos mínimos", e isso deveria ser entendido como o "conjunto de conteúdos que não podem deixar de ser dados em uma determinada série ou determinado nível". Esse fato foi considerado pelo grupo na escrita da coleção Matemática e também o uso do método heurístico.

Em George Pólya, Martha fundamentou a utilização de estratégias heurísticas no processo da descoberta. Segundo Pólya (1978, p. 181), em seu livro $A$ arte de resolver problemas, “[...] heurístico, como adjetivo, significa 'servindo para descobrir"'.

Outros princípios foram considerados e esclarecidos por Martha Dantas no livro de sua autoria, publicado em 1987, destinado aos professores. Para a elaboração das fichas, os "casos particulares" deveriam "conduzir à formulação de leis gerais" e as "relações de analogia deveriam ser estabelecidas para alcançar as conclusões” (DANTAS, 1987, p. 16). Segundo Martha Dantas, a analogia deveria ser utilizada para enfatizar procedimentos relacionados, e para isso, os autores fizeram uso na escrita da coleção de expressões como: do mesmo modo, procedendo como se fez acima e analogamente, que foram encontradas em várias fichas da coleção. A autora toma novamente como referência o livro de George Polya: "G. Polya recomenda recorrer à analogia para resolver um problema quando nos diz: Se você não conseguir resolver um problema, procure resolver, antes, um problema correlato" (DANTAS, 1987, p. 5).

Martha acrescentou a esses princípios que "[...] os fatos concretos devem preceder idéias abstratas". Também apontou para o cuidado com a linguagem utilizada, que deveria ser, "[...] tanto quanto possível, a linguagem do aluno" e, finalmente, que a atividade do aluno fosse “[...] provocada ao máximo, respeitando o seu ritmo” (DANTAS, 1987, p. 16).

Alguns "conteúdos modernos" foram mantidos pelos autores, como o estudo das noções elementares da teoria dos conjuntos, as noções de relação e aplicação, o estudo da geometria por meio das transformações geométricas e das propriedades de espaço vetorial, apesar de não ser mais realizado um estudo explícito dessa estrutura. Essa permanência na abordagem do ensino da Geometria já havia sido apontada nos trabalhos de Freire (2009) e Camargo (2009) ao analisarem as outras coleções deste grupo.

Para a explicação dos conceitos de relação e aplicação, os autores apresentaram vários exemplos, dentre eles exploraram as relações de parentesco entre pessoas de uma família: "Carlos é ‘tio de’ Denise", "Antônio é ‘tio de’ Mônica", "Paulo é 'tio de’ Lúcia e de Carlos”. Depois de vários exemplos apresentados pelos autores, os alunos são convidados a construir o gráfico de flechas, que permite relacionar o conjunto P, dos países formados por França, Brasil, Alemanha e Portugal ao seu idioma oficial. Além do conjunto P, são enumerados os elementos do conjunto I, referentes aos idiomas oficiais: francês, português, alemão e espanhol. Na sequência, seguem as perguntas que devem ser respondidas pelos alunos no espaço reservado no livro (Figura 1) (DANTAS, 1987, p. 28).

\footnotetext{
${ }^{4}$ Atualmente, corresponde às três séries do Ensino Médio.
} 
Figura 1. Gráfico de flechas

\begin{tabular}{|l|}
\multicolumn{1}{c|}{$\mathrm{P}$} \\
\hline França . \\
Brasil . \\
Alemanha . \\
Portugal . \\
\hline
\end{tabular}

\begin{tabular}{|l|}
\multicolumn{1}{c|}{ I } \\
\hline . francês \\
- português \\
. alemão \\
. espanhol \\
\hline
\end{tabular}

De cada elemento P parte uma flecha?

resposta:

Por que?

resposta:

De algum elemento $P$ parte mais de uma flecha? resposta:

No exemplo dado, a relação "idioma oficial” é uma aplicação de P em I.

Fonte: Primeiro volume da coleção Matemática.

Seguem-se outros exemplos de relações que são aplicações, e outros que não são aplicações. Todos eles deveriam ser completados pelos alunos, semelhante ao exemplo exibido na Figura 1. Ao final dessa ficha, os autores questionaram os alunos:

Será que você pode dizer quando é que uma relação é uma aplicação? Resposta:

Ao comentar em seu livro destinado aos professores a introdução do conceito de aplicação no primeiro volume da coleção Matemática, Dantas (1987, p. 22) argumentou que “[...] o conceito de aplicação é um dos conceitos fundamentais da Matemática, defendemos a sua introdução mais cedo, desde que se encontre uma abordagem adequada ao nível do aluno ao qual o conceito é apresentado".

A própria autora reconheceu que esse conceito era normalmente apresentado na $8 .^{a}$ série, mas afirmou que, com as experiências já realizadas com essa ficha, o aluno entendia o conceito de aplicação e era induzido a escrever uma definição para esse conceito.

Com relação ao ensino da geometria, Martha Dantas defendeu em um artigo de sua autoria que o professor poderia utilizar translações, simetrias, homotetias e rotações para mostrar propriedades da geometria euclidiana. No mesmo artigo, também apontou que, em suas experiências com os alunos, observou que eles não sentiam dificuldade em mostrar que "[...] ângulos alternos internos são congruentes porque um pode ser obtido do outro por simetria central, e ainda, que ângulos correspondentes são congruentes porque um pode ser obtido do outro por translação" (DANTAS, 1995, p. 277). 
Todos esses exemplos foram explorados pelos autores na coleção Matemática, e também nas coleções anteriores. Conforme já ressaltado, nessa última coleção há uma mudança na abordagem dos conteúdos matemáticos, que, na grande maioria dos textos, os apresenta interrogando os alunos, com propostas de conduzi-los para suas próprias descobertas.

\section{Considerações finais}

A experiência dos autores com a escrita e experimentação das primeiras coleções nas escolas foi fundamental para a produção da coleção Matemática, na qual os autores realizaram uma grande revisão de conteúdos, defenderam suas posições na manutenção de outros, e apresentaram uma nova metodologia para a introdução aos conceitos matemáticos, já que a proposta dessa coleção era voltar à atenção para os alunos e estar atentos às suas necessidades, em busca de uma melhor aprendizagem da Matemática.

Avaliou-se que as estratégias dos autores para a produção das primeiras coleções estão muito centradas nas concepções de ensino de Matemática de Catunda, conforme se pôde apreender nos depoimentos de Martha Dantas. De fato, no estudo feito para situar a coleção Matemática em relação às outras coleções publicadas por esse grupo, observou-se o excesso de formalismo e a tendência para a abstração que marcou as primeiras produções do grupo. A intuição, apontada por Catunda como um elemento importante no processo de ensino da Matemática, passa a ser explorada em atividades e exemplos dentro da própria Matemática, desligada da realidade vivenciada pelo aluno no ambiente escolar e social.

Durante o período de escrita da coleção Matemática, Martha Dantas havia ressaltado que matemáticos e professores de Matemática haviam reconhecido que a Matemática mudara e novos conceitos precisavam ser introduzidos nas escolas, mas era preciso se preocupar com o modus faciendi, ou seja, a maneira como esses conteúdos poderiam ser apresentados aos alunos. Com isso, o enfoque dos autores não estava mais no estudo formal das estruturas matemáticas, como ficou evidente no estudo das primeiras coleções. As estruturas estavam presentes na obra, mas seu estudo explícito foi substituído por atividades e exercícios que as colocassem em evidência.

\section{Referências}

BRASIL. Lei $n^{\circ}$ 5.692, de 11 de agosto de 1971. Fixa diretrizes e bases para o ensino de $1^{\circ} \mathrm{e}$ $2^{\circ}$ graus, e dá outras providências. Diário Oficial da União, Brasília, 12 ago. 1971. Seção 1. Disponível em: <http://www2.camara.leg.br/legin/fed/lei/1970-1979/lei-5692-11-agosto1971-357752-publicacaooriginal-1-pl.html>. Acesso em: 8 jun. 2016.

CAMARGO, K. C. O ensino da geometria nas coleções didáticas em tempos do movimento da matemática moderna na capital da Bahia. 2009. 168 f. Dissertação (Mestrado em Educação Matemática) - Universidade Bandeirantes de São Paulo, São Paulo, 2009 . 
Gomes, L. P. S.

CATUNDA. O. Depoimento. Cadernos do IFUFBa, Salvador, v. 1, n. 3, p. 87-102, jul.1985.

CERTEAU, M. A escrita da história. 2. ed. Rio de Janeiro: Forense Universitária, 2010.

A invenção do cotidiano 1: artes de fazer. 15. ed. Petrópolis: Vozes, 2008.

CHARTIER, R. Por uma sociologia histórica das práticas culturais. In: A história cultural entre práticas e representações. Rio de Janeiro: Bertrand Brasil, 1990. p. 13-28. (Coleção Memória e sociedade).

CHOPPIN, A. História dos livros e das edições didáticas: sobre o estado da arte. Educação e Pesquisa, São Paulo, v. 30, n. 3, p. 549-566, 2004. Disponível em: < http://www.scielo.br/ pdf/ep/v30n3/a12v30n3.pdf >. Acesso em: 9 jun. 2016.

DANTAS, M. M. S. Depoimento. Cadernos do IFUFBA, Salvador, v. 8, n. 1-2, p. 63-84, jul. 1996.

Discurso de abertura do I Congresso Nacional do Ensino da Matemática. In:

TAHAN, M. Didática da matemática. 3. ed. São Paulo: Saraiva, 1967. v. 1.

Ensino da matemática: um processo entre a exposição e a descoberta. Salvador:

Centro Editorial e Didático da UFBA, 1987.

. Matemática moderna na escola secundária: uma análise crítica. Estudos IAT, Salvador, v. 2, n. 4, p. 106-112, mar. 1989. 1993.

. Uma mestra e sua vida. Cadernos do IFUFBA, Salvador, v. 6, n. 1-2, p. 11-36, out.

Pesquisa no ensino de matemática: as transformações geométricas e o ensino da geometria na $7^{\mathrm{a}}$ e $8^{\mathrm{a}}$ séries. Cadernos do IFUFBA, Salvador, v. 7, n. 1-2, p. 260-287, mar. 1995.

Sobre a metodologia da matemática. 1971. 38 f. Tese (Professor titular) Faculdade de Educação, Universidade Federal da Bahia, Salvador, 1971.

DANTAS, M. M. S. et al. Matemática. Salvador: Contraste, [19-- ?].

DIAS, A. L. M. Engenheiros, mulheres, matemáticos: interesses e disputas na profissionalização da matemática na Bahia (1896-1968). 2002. 320 f. Tese (Doutorado em História Social) - Universidade de São Paulo, São Paulo, 2002.

FELIX, L. Exposé moderne des mathématiques élémentaires. Paris: Dunod, 1966. (Collection Universitaire de mathématiques).

Mathématiques modernes: enseignement elémentaire. Paris: Albert Blanchard, 1960.

FREIRE, I. A. Ensino de matemática: iniciativas inovadoras no Centro de Ensino de Ciências da Bahia (1965-1970). 2009. 102 f. Dissertação (Mestrado em História das Ciências) - Universidade Federal da Bahia, Salvador, 2009. 
GOMES, L. P. S.; MIORIM, M. A. Práticas escolares de matemática no Instituto Nossa Senhora da Piedade em Ilhéus: desafíos para a educadora baiana Martha Dantas. Bolema: boletim de educação matemática, Rio Claro, v. 29, n. 53, p. 867-886, 2015. Disponível em: <http:/ /dx.doi.org/10.1590/1980-4415v29n53a05>. Acesso em: 10 jun. 2016.

KLINE, M. O fracasso da matemática moderna. São Paulo: IBRASA, 1976.

POLYA, G. A arte de resolver problemas. Rio de Janeiro: Interciência, 1978.

SILVA, J. S. Transformações geométricas. Lisboa: Associação de Estudantes da Faculdade de Ciências, 1950.

Artigo recebido em 24/06/2015. Aceito em 05/01/2016.

Endereço para contato: Universidade Estadual de Santa Cruz, Departamento de Ciências Exatas e Tecnológicas, Campus Soane Nazaré de Andrade, Rodovia Jorge Amado, km 16, Bairro Salobrinho, CEP 45662-900, Ilhéus, BA, Brasil. 